\title{
DOMINGOS PELLEGRINI JR.: CONSIDERAÇŌES SOBRE UM CONTISTA QUE SE FAZ POETA
}

Rosse Marye Bernardi Universidade Federal do Parand́

\begin{abstract}
RESUMO
O contista Domingos Pellegrini Jr. cedo descobriu os caminhos da invenção e da surpresa e felizmente cedo foi descoberto pela crítica e pelo público. Mas existe também um Pellegrini poeta que, alèm de extravasar seu lirismo nas imagens e metáforas de sua prosa contundente, também faz incursōes formalmente poéticas. É este Pellegrini ainda tímido (talvez para sempre tímido) que nos propo. mos revelar pela leitura de seus poucos poemas publicados.
\end{abstract}

Domingos Pellegrini Jr., contista, cedo descobriu os caminhos da invenção e da surpresa e, felizmente, cedo foi descoberto pela crítica e pelo público.

Colocando o domínio consciente da técnica a serviço de uma temática que se enraiza fundo na nossa realidade, captando o que ela tem de dramático, insólito e lírico, Pellegrini, em 0 homem vermelho e Os meninos, reiventa o mundo. ${ }^{1}$ Na primeira obra, sob a visada de sua aguda percepção, os textos surgem como radiografias estéticas de momentos da vida ou da subvida de seres marginalizados e perplexos. Posseiros, fugitivos, barrageiros, caminhoneiros e camelôs são os antiheróis de uma prosa pungente, que desfila o absurdo de situações típicas e médias do interior paranaense. Ou seria do interior brasileiro?

'PE LLEGRINI JR., Domingos. O homem vermelho. Rio de Janeiro, Civilização Brasileir8, 1977, —. Os meninos. São Paulo, Vertente, 1977. 
Já em Os meninos, os contos são como versões multifacetárias do estado de infância e de adolescência. Neles, onde, muitas vezes, convivem o real e o imaginário, a expressão se suaviza, apre€ndendo sensações mais finas, não raramente atingindo a pura poesia. Poesia da infância - reino da posse - que o adulto, signo vivo da perda, visita no colégio deserto. ${ }^{2}$ Mas também e, principalmente, a poesia das palavras, imagens e metáforas que recuperam, metamorfoseando, o lirismo que existe nas coisas e nos fatos. Assim, foi sem muitas surpresas que encontramos o poeta Domingos Pellegrini Jr publicado, embora timidamente, entre outros paranaenses, na antologia 4 poetas $^{2}$. E o reencontramos, mais recentemente, na mensagem de "Falta p.ouco" ${ }^{3}$, em Raposa magazine.

A produção a que temos acesso é pequena - cinco poemas ao todo - mas suficiente para nos confirmar a coerência expressional e temática de um artista cujo compromisso maior é o próprio homem. Os textos publicados em 4 poetas não foram, evidentemente, selecionados aleatoriamente. Apesar de seu caráter autotélico ou sem renunciar a este caráter, eles apresentam-se como uma série, espécie de roteiro de um eu em situação: um poeta diante da poesia e diante do mundo.

O poema de abertura, "Primeira página", reflexivo e auto-referencial, pode ser visto como a sintese da postura poética do autor. Nele, dois aspectos basicamente chamam a atenção - de um lado, o teor metalingüístico, isto é, o desvendamento do texto, construido aos olhos do leitor:

"O primeiro verso há de ser bonito.

Ou falarei de caspa na primeira página?

Ou tudo isso, não sei, os livros

e suas páginas, talvez sejam mitos."

constituindo-se a reflexão sobre o ato de poetar - a inquirição sobre a expressão, temática e função do poeta - essência e incidência textual. Esta atitude não deve, no entanto, ser avaliada como mera incursão experimentalista, mas como o próprio núcleo problemático do texto, que se volta inicialmente para a denúncia da poesia como espaço de ocultação e traição do real.

A oferta do belo e do absurdo recusa-se o poeta em busca de seu próprio caminho:

"Certas horas, entre os livros,

como num quarto com inseticida

sendo na máquina - atrás da saída,

a saída."

(4 P - p. 3)

1977. Os moninos. São Paulo. Vertente, 1977.

2 PELLEGRINI JR., Domingos. A visita. In: Os maninos, p. 84.

${ }_{3}^{3}$ PELLEGRINI JR., Domingos et alii. 4 pootas. s. 1., Cooperativa de Escritores, s. d. p. 1 - 15

${ }^{4}$ PE LLEG RINI JR., Domingos. Fal ta pouco. Raposa Magazine (1):11. maio 1981. 
caracterizando-se então um segundo aspecto, que privilegia o caráter subjetivo - nunca indiscreto ou piegas - desta poesia.

Referenciando Ezra Pound, num belo exemplo de intertextualidade:

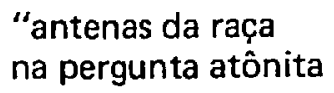

(4 P. - p. 4)

o próprio ritmo enfatiza a angústia e perplexidade do poeta, que sente a poesia como uma função específica: a antenação com a contemporaneidade, com a aqui e o agora, com toda a dor do mundo. Com uma sofrida lucidez o poeta se entrega:

"Abro a janela. As vilas rodeiam meus livros, cinturão de sarnas."

(4 P. - p. 4)

"Diante da xícara" e "Aula noturna", os poemas que se seguem, têm em comum o tom confessional, memorialista. $O$ primeiro desvela a paisagem da infância, revisitada de maneira não linear. A xícara de café, motivação básica, fragmenta-se prismaticamente, apreendendo múltiplas sensações, numa densa tessitura de lembranças:

"Do café, lembro o cheiro doce coando de manhãs que eu acordava com ossos muito, muito mais pequenos;

Do café lembro o coador, pigarros

e botas madrugando no assoalho; cheiro de estopa, de tulha nos quartos;

(4 P. - p. 4-5)

A linguagem deliberadamente discursiva e a confissão direta criam, paradoxalmente, o clima poético. Verdadeira poesia em prosa, os versos e parágrafos longos desencadeiam associações evocativas da infância, interpenetradas pela dimensão existencial. A superposição de imagens engendra a emoção lírica, na captação de um mundo construído de concretas descobertas, onde as palavras se confundem com os objetos:

"formigas na borra, flores e açúcar.

o pó-de-serra das escarradeiras, fumo-de-corda, palha, saliva preta;"

(4 P. - p. 4)

e onde se surpreende a morte, no espanto da casa, "enquanto todos sopravam café e bebiam silêncio".

No entanto, através da reiteração sistemática e ritmica da forma 
verbal "lembro", percebe-se que é sempre bem nitida a distância entre o passado e o presente. Por isso, no monólogo do adulto não se recupera a generalização abstrata da infância e nem ela é vista sob uma perspectiva meramente afetiva. Em vez disso, o que se apreende, criticamente, através do lugar comum recuperado, é o desgaste dos sentimentos:

"e de pé na sala, de capote, o pai falando café frio, fraco e fedido. antes de sair erguendo a gola, sem saber que ra noite de geada"

(4 P. - p. 5 )

ou o alinhavo da decadência econômica familiar e. por extersão te to dos os envolvidos na saga do café:

"E, do café, lembro a caderneta com algarismos pretos apertados

em equilibrismos, até que o tombo

deitou o vô na terra; o cafezal

virou mapa suado num cartório,"

(4 P. - p. 6)

Assim, a xicara é o espelho côncavo que reflete imagens reduplica. das, onde se confundem e coexistem os planos objetivo e subjetivo, ligados à vivência do poeta. Café-cheiro-de-infância, café-saudade, mas, também, café-ouro, café-ferrugem, simbolo da subsistência e dos sonhos perdidos:

"Do café lembro essa palavra:

ouro

que virou ferrugem, até virar

em toalha tecida de absurdo

esta sobremesa,

(4 P. - p. 6)

negra."

Em "Aula noturna" temos o grito de contestação às convenções, às teorizações, ao instituido:

"Certas coisas

nunca conseguiram me ensinar. Um supositório

vocè enfia à força na boca de um homem

mas força nenhuma o fará gostar."

(4 P. - p. 7)

Ao longo do poema, que se faz através da potencialização de imagens cotidianas e da incorporação do coloquial no plano da escritura poética, percebe-se um antagonismo radical, um jogo dialético que se processa em termos de oposição entre o imposto e o vivenciado, entre o real e o mascaramento do real. Mas, apesar do tom de desencanto e so- 
frimento, a imagem final é de esperança. A janela, abrindo-se para livres espaços, simboliza a libertação do espírito, sequioso da verdade - estrela "viva/no vento/mesmo depois de morta.":

"Quando pisco, professor. desconfio; não é sono.

E quando sorrio é de tristeza

\author{
diante da escuridão \\ do quadro-negro. \\ Pela janela, \\ procuro estrelas." \\ (4 P. - p. 8)
}

A esperança também está, paradoxalmente, presente no último e longo poema da série, que recusa um título à maneira tradicional. Traz, em vez disso, como uma espécie de apresentação ou rubrica: "Poema escrito em guardanapo, papel de embrulho, papel de cigarro", incorporando-lhe, explicitamente, uma referência à situação criativa, urgente e inesperada. $O$ texto divide-se em quatro partes, melhor diríamos em quatro cenas - "antes do almoço", "depois do almoço", "no meio da tarde", "no fim da tarde", tecendo, com suas implicações cronológicas, o roteiro de um individuo em plena crise econòmica:

"Bebo silêncio, sem espuma.

Os garçons vão arrumando as mesas.

Beberam leite, acalmaram as úlceras, estendem toalhas com passes de mágica.

Agora vigiam com as mãos nas costas.

Se me coçar acenderão isqueiros, se ficar quieto trarão o cardápio.

Peço mais uma cerveja, das pequenas

- e queria que fosse ainda maior.

Não aguento mais, meu pai, sem urinar.

Mas, se levantar, me arrumam a mesa, terei que comer ou pagar as cervejas."

(4 P. - p. 9 - 10)

A descrição levada a efeito é objetiva e literal e, mais que isso, prosaica, porque prosaica é a realidade banal e bruta que a poesia não pode ignorar. A necessidade de não se desprender do vivido, de não difarçálo com sutilezas, leva o poeta a recusar todas as insinuações metafóricas. A fome, assunto terrivel e antipoético, é trazido à condição de assunto poético por força da própria palavra, determinando a originalidade do discurso e a temática de preocupação social.

Paradoxalmente, a opção pela primeira pessoa é, no caso, um re- 
curso para esconder o poeta e deixar falar o homem marginalizado pelo sistema. Quase personagem de um longo monólogo, o eu que aparece no texto é um eu a nivel plural, em constante transformação, sintetizando situações de desemprego, de miséria, de exploração do homem pelo homem.

Enquanto estrutura, o texto se constrói, conforme comentamos anteriormente, de cenas, à maneira de um poema dramático. Na primeira cena, a linguagem crua e incisiva traduz o desespero em imagens que muitas vezes atingem o grotesco. Um homem faminto não vê belezas à sua volta, reduzindo o mundo às suas próprias e imperiosas necessidades:

"A fome também tem relógio, em dez minutos sentaram dez estômagos, olha como comem. A facilidade com que abrem a boca, a carteira.

Se eu falar que perdi a carteira... Quem sabe se puxar fora os bolsos como linguas. Ou pedir mais cerveja, mais, até virar um pardal.

Em boteco é sempre segunda-feira.

Aqui no restaurante, é sexta

- bacalhoada. Olha como comem.

Que remédio. Urino. Peço bacalhoada."

(4 P. - p. $10 \cdot 11$ )

"Depois do almoço", segunda cena, o homem, última vítima na arena do restaurante, mesmo sem dinheiro para pagar a conta, reencontra a sua dignidade e o seu humor. A própria expressão acompanha este evoluir, alternando-se as imagens em ritmo acelerado, acompanhando o pensamento que hesita entre humilhar-se e fugir:

"não encha. Pensa, minha barriga, a cabeça cansou. Quem sabe se pedir perdão, esse pedaço de alma que estende sangrando a mão para pegar navalhas. Não. 
A esperança é uma flor roxa

que nasce de trouxa

numa mesa cie bar.

Mas eu tenho esperança, sim, eu tenho. Tenho pernas. Com licença, senhores,

depois que guardar a caneta

vou sair correndo. Eu sou um homem, apesar de tudo, com fôlego.

(4 P. - p. 13)

Neste momento - lobservar que a locução "depois que guardar a caneta/ vou sair correndo.", remete metalingüisticamente à própria composição poétical - o poeta se encontra com o homem em estreita solidariedade. Não é, porém, uma solidariedade feita de retórica, de pena, ou de defesa do oprimido. Mas uma solidariedade de fato, na medida em que a situação não é vista de fora, como um espetáculo, mas a partir de uma visão de dentro, apreendida criticamente através da parodia e da ironia.

Na dialética da vida, o sério sucede o cômico, ou melhor, é o seu reverso. "No meio da tarde", atropelado pelo tempo, "ao mormaço de petróleo e desemprego", ele conscientemente sabe que caminha para a crise:

"A crise, meus senhores, é uma vaca
com tetas de berrugas,
muge
com sirenes das indústrias pretas
bafo de detergente e inseticida,
mas parirá, senhores,
um bezerro
que ficará de pé no primeiro minuto,
ainda úmido, e dentro duma hora
berrará anunciando ao mundo
a inauguração do mundo."

(4 F. - p. 14)

Mas o homem recusa o fracasso de sua vida. "No fim da tarde", meninos o rodeiam na paisagem. Meninos que perdem os seus brinquedos e não choram, engolindo ar que "entra (como) uma punhalada de luz". O trecho final tem como núcleo a busca dramática para prosseguir na luta. Sem argumentos convincentes, o homem se apega à esperança - absurda esperança - que ele mesmo reconhece precária e passa- 
geira. Fatalisticamente, o pensamento se debruça sobre si mesmo; depois da noite vem um novo dia, e o futuro, embora sem perspectivas imediatas, é sempre imprevisível:

“No coração, esta pedra pequena que vai diminuindo, vira estrela e amanhecerá como uma vela que soluça, mas não apaga.

Como eu acho que já disse, amigo, eu tenho esperança."

$$
\text { (4 - P. p. 15) }
$$

Em "falta pouco" - texto publicado isoladamente nas páginas de Raposa magazine, a temática se amplia, tocando o transcendente.

Primorosamente construído, elaborando-se da redundante repetição da locução "falta pouco", núcleo sintático e semântico de um pensamento dialético, o poema expõe o real e o ideal. $O$ mundo em que vivemos e o mundo em que deveríamos viver. $O$ que śmos e o que deveríamos ser:

"Falta pouco, sim

falta

pouco

para o gesto esquecer seu uso e encarar seu destino

e a mão deixar de se olhar como instrumento para se ver como fonte

e será tão desnecessária que penderá rendida como um dia se rendeu

o rabo, que muitos pensam que caiu mas na verdade se embutiu em nós.

$E$

falta pouco

apenas incontáveis vidas

para que a razão vire sabedoria

- corpo veja e escute pelas vibrações

pouco a pouco deixando de ser corpo

e o espírito continuará viajando para ser 
coisa tão impensável que não precisará

nem de energia nem de ciência

e será como

apenas como exemplo

Deus ou seu templo."

(R.M. p. 11)

Para Domingos Pellegrini Jr, contista e poeta, a arte é o espaço privilegiado onde se realiza um constante esforço de superação das contradições humanas. No entanto, o próprio fato de estarmos diante de uma obra em elaboração, impede qualquer juizo definitivo. O contista está merecidamente consagrado. Quanto ao poeta, esperemos que a inspiração e a técnica conduzam sua poesia e sua poética para insuspeitados e gratificantes caminhos.

\section{RÉSUMÉ}

Le conteur Domingos Pellegrini Jr. découvrit três tôt les chemins de l'invention et du suspense et heureusement fut très tôt découvert par la critique et le public. Mais existe également un Pellegrini poète qui en plus de déverser son lyrisme dans les images et les images et les métaphores de sa prose acerbe, il fait aussi des incursions formellement poétiques. C'est ce Pellegrini encore timide (peut-être timid pour toujours) que nous nous proposons réveler par la lecture de ses poèmes déjà publiés, qui sont en petit nombre.

(Rosse M. Bernardi)

\section{REFERÊNCIAS BIBLIOGRÁFICAS}

1 PELLEGRINI JR., Domingos. Falta pouco. Raposa Magazine (1):11, maio 1981.

2 - O homem vermelho. Rio de Janeiro, Civilização Brasileira, 1977.

3 - Os meninos. São Paulo, Vertente, 1977.

4 et alii. 4 poetas. s. I., Cooperativa de Escritores, s. d. 